\title{
Separation of Fructosyl Oligosaccharides in Maple Syrup by Using Charged Aerosol Detection
}

\author{
Kanta Sato (D), Tetsushi Yamamoto, Kuniko Mitamura and Atsushi Taga * \\ Pathological and Biomolecule Analyses Laboratory, Faculty of Pharmacy, Kindai University, 3-4-1 Kowakae, \\ Higashiosaka 577-8502, Japan; kantasato713@gmail.com (K.S.); yamatetsu@phar.kindai.ac.jp (T.Y.); \\ mitamura@phar.kindai.ac.jp (K.M.) \\ * Correspondence: punk@phar.kindai.ac.jp; Tel.: +81-6-6721-2332
}

Citation: Sato, K.; Yamamoto, T.; Mitamura, K.; Taga, A. Separation of Fructosyl Oligosaccharides in Maple Syrup by Using Charged Aerosol Detection. Foods 2021, 10, 3160 . https://doi.org/10.3390/foods 10123160

Academic Editors: Ana M. Ares and José Bernal del Nozal

Received: 4 November 2021

Accepted: 16 December 2021

Published: 20 December 2021

Publisher's Note: MDPI stays neutral with regard to jurisdictional claims in published maps and institutional affiliations.

Copyright: (c) 2021 by the authors. Licensee MDPI, Basel, Switzerland. This article is an open access article distributed under the terms and conditions of the Creative Commons Attribution (CC BY) license (https:/ / creativecommons.org/licenses/by/ $4.0 /)$.
Abstract: Fructosyl oligosaccharides, including fructo-oligosaccharide (FOS), are gaining popularity as functional oligosaccharides and have been found in various natural products. Our previous study suggested that maple syrup contains an unidentified fructosyl oligosaccharide. Because these saccharides cannot be detected with high sensitivity using derivatization methods, they must be detected directly. As a result, an analytical method based on charged aerosol detection (CAD) that can detect saccharides directly was optimized in order to avoid relying on these structures and physical properties to clarify the profile of fructosyl oligosaccharides in maple syrup. This analytical method is simple and can analyze up to hepta-saccharides in $30 \mathrm{~min}$. This analytical method was also reliable and reproducible with high validation values. It was used to determine the content of saccharides in maple syrup, which revealed that it contained not only fructose, glucose, and sucrose but also FOS such as 1-kestose and nystose. Furthermore, we discovered a fructosyl oligosaccharide called neokestose in maple syrup, which has only been found in a few natural foods. These findings help to shed light on the saccharides profile of maple syrup.

Keywords: HPLC; charged aerosol detection; CAD; fructosyl oligosaccharide; FOS; maple syrup; neokestose; 1-kestose; nystose

\section{Introduction}

Maple syrup is a popular natural sweetener made by boiling sap from sugar maple trees. As the season progresses, maple syrup's color darkens, and it is classified into four grades: golden, amber, dark, and very dark [? ]. Maple syrup has various biological effects, and it has also been reported that different grades of maple syrup could have different biological effects [? ? ? ? ]. Although maple syrup has a low glycemic index (GI), it is mostly sucrose with a small amount of glucose and fructose [? ? ? ? ]. It was reported that maple syrup contains pentoses, such as xylose, arabinose, and ribose, and polysaccharides, such as inulin [? ? ]. Our previous study discovered that maple syrup contains a fructosyl oligosaccharide known as blastose [? ]. Furthermore, this study also suggested the presence of an unidentified compound in maple syrup that was considered to be fructosyl oligosaccharide with a polymerization degree of at least three.

Recently, fructosyl oligosaccharides have gained popularity, with a 1-kestose, nystose and 1-fructofuranosylnystose serving as examples (Figure ??). These saccharides are known as fructo-oligosaccharides (FOS); they have been reported to have functions such as indigestibility and prebiotics, which are beneficial to human health [? ? ]. Although these saccharides have been found in natural products such onion, burdock, and banana [? ? ? ? ? ], the amounts are minute. It is critical to quantify FOS in order to make effective use of natural products containing FOS as functional foods. However, due to the capping of the aldose-reducing terminal by fructose, FOS cannot be analyzed with high sensitivity using derivatization methods. As a result, there is a need for an analytical approach with high sensitivity that can directly analyze FOS. 
1-Kestose

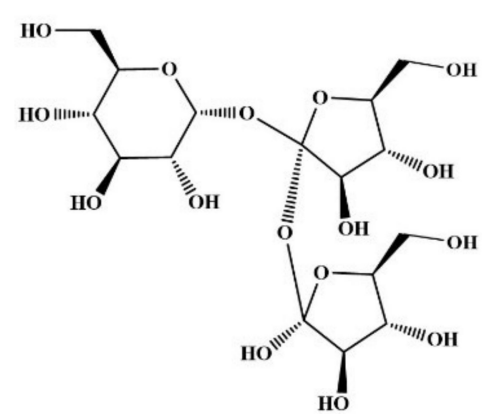

Nystose

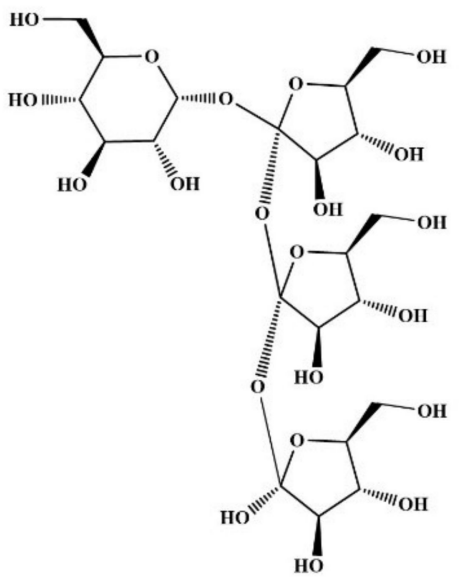

1-Fructofuranosylnystose

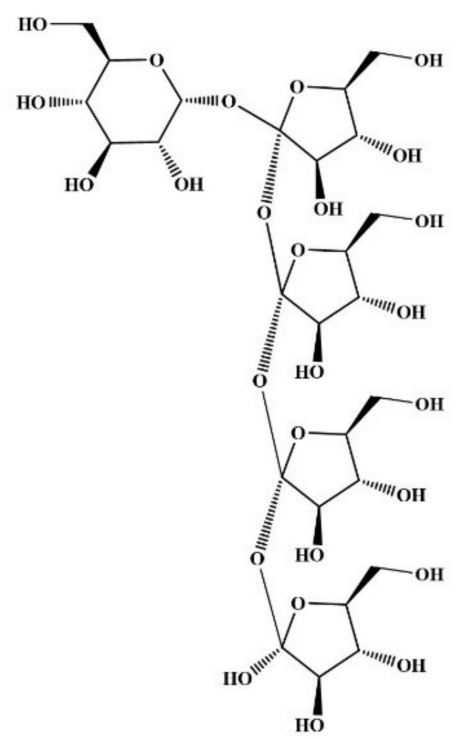

Figure 1. The structures of 1-kestose, nystose, and 1-fructofuranosylnystose as the representative FOS.

Charged aerosol detection (CAD), refractive index detection (RID), and pulsed amperometric detection (PAD) are analytical methods for saccharide detection [? ? ? ]. Although RID is used for routine analysis and the analysis of known compounds, it has been reported that the LOQ for saccharides analysis by HPLC-RID is in the $0.18-0.30 \mathrm{~g} / \mathrm{L}$ range [? ]. On the other hand, PAD can analyze several saccharides with high resolution; it requires an anion exchange column and sodium hydroxide as the mobile phase. Because desalting is required, it is challenging to identify unidentified compounds in natural products. As a solution to these issues, CAD has become widely used in recent years. CAD is more versatile and has a more comprehensive detection range than RID. Its capabilities include detecting a wide range of semi- and non-volatile compounds such as saccharides but also lipids, amino acids, and peptides [? ? ? ? ]. Its responsiveness is independent of the analyte's molecular structure or physical properties. Therefore, unknown compounds can be quantified using known compounds [? ]. These properties are ideal for quantifying neutral saccharides with no UV absorption and analyzing compounds that cannot be derivatized, such as FOS. Because gradient elution for CAD is possible, it is possible to analyze unidentified oligosaccharides that are likely to be overlooked by RID methods in the analysis of natural products. As a result, CAD can detect trace amounts of unidentified oligosaccharides found in natural products. Although several CAD applications for analyzing aldoses such as glucose have been reported [? ? ], it has not been reported for analyzing saccharides fructosyl oligosaccharides including FOS.

This study aims to optimize the analysis method using FOS standards by hydrophilic interaction chromatography (HILIC)-CAD to clarify the profile of fructosyl oligosaccharides, including FOS in maple syrup. This optimized method is simple, compact, and reliable, and reproducible. While the RID method could only detect sucrose, glucose, and fructose, this optimized method using CAD was able to observe the several rare saccharides as well as the major saccharides such as sucrose. In addition, its quick application was used to identify and quantify several FOS in maple syrup precisely. Furthermore, we discovered that maple syrup contained one FOS, which is rarely reported in natural foods.

\section{Materials and Methods}

\subsection{Reagents and Chemicals}

Fructose, glucose, and sucrose were purchased from Nacalai Tesque, Inc. (Kyoto, Japan). Nystose, 1-kestose, and 1-fructofuranosylnystose were purchased from FUJIFILMWako Pure Chemicals Co (Osaka, Japan). Maple Farms Japan, Inc. (Osaka, Japan) gener- 
ously provided all maple syrup of grade A and sap. These maple syrups are made from sugar maple (Acer saccharum) and produced by Bascom Maple Farms, Inc. (Acworth, NH, USA). All other chemicals were of the highest purity and obtained from Nacalai Tesque, Inc. (Kyoto, Japan).

\subsection{Sample Preparation}

All saccharide standards were prepared at the following concentrations: $0.5,1.0,5.0$, $10,25,50,75$, and $100 \mu \mathrm{g} / \mathrm{mL}$. The maple syrup was dried and then dissolved in water. This solution was centrifuged for $5 \mathrm{~min}$ at $3000 \times \mathrm{g}$. The supernatant was filtered via a $0.45 \mu \mathrm{m}$ filter (Merck Millipore, Darmstadt, Germany), and acetonitrile was added to the filtrate to adjust the solvent concentration to $75 \%$ acetonitrile.

\subsection{Analysis by High-Performance Liquid Chromatography with CAD (HPLC-CAD)}

Maple syrup samples were analyzed using an LC 10 Advp system (Shimadzu Corporation, Kyoto, Japan) equipped with a Corona Veo detector (Thermo Fisher Scientific, Inc., Waltham, MA, USA). Separation was performed using an Asahipak NH2P-50 4E column ( $5 \mu \mathrm{m}, 4.6 \mathrm{~mm}$ internal diameter $\times 250 \mathrm{~mm}$, Showa Denko K.K., Tokyo, Japan) as an HILIC column. The mobile phase consisted of deionized water (solvent A) and acetonitrile (solvent B) with multi-gradient elution in $75 \%$ solvent B from 0 to $10 \mathrm{~min}$ and 75 to $50 \% \mathrm{~B}$ from 10 to $30 \mathrm{~min}$. At room temperature $\left(\sim 23^{\circ} \mathrm{C}\right)$, the flow rate of $1 \mathrm{~mL} / \mathrm{min}$. The injection volume was set to $20 \mu \mathrm{L}$. The data processing was carried out using Chromeleon 7.2.2 software (Thermo Fisher Scientific, Massachusetts, MA, USA). The pure nitrogen gas for the CAD was flowed by an AT-2NP-CAD (AIR-TEC Co., Kanagawa, Japan). The sampling rate was set to $5.0 \mathrm{~Hz}$ with a filter constant of $5.0 \mathrm{~s}$. The response and signal correction power function was set to 1.0. The fractionate of a target oligosaccharide was carried out using an Asahipak NH2P-50 10E column $(5 \mu \mathrm{m}, 10.0 \mathrm{~mm}$ internal diameter $\times 250 \mathrm{~mm}$; Showa Denko K.K.) with $75 \%$ acetonitrile as the mobile phase was. A flow rate of $2 \mathrm{~mL} / \mathrm{min}$ was used for isocratic elution with Adjustable Flow Splitter (Thermo Fisher Scientific Inc., Waltham, MA, USA) as a post-column type splitter. The split ratio was 1:20, with the low-flow outlet directed to CAD. The remaining ( $95 \%)$ volume was then collected from the splitter's high-flow outlet. The other conditions were as previously described.

\subsection{HPLC-CAD Method Validation}

Based on the International Council for Harmonization and Technical Requirements (ICH) guidelines [? ], the developed HPLC-CAD method was validated in terms of concentration range, linearity, limit of detection (LOD), limit of quantitation (LOQ), precision, and recovery. All experiments were performed at least three times.

\subsubsection{Linearity}

The linearity experiments were performed with eight different concentrations (0.5-100 $\mu \mathrm{g} / \mathrm{mL}$ ) of standards. Each calibration curve was fitted to a linear, quadratic, or logarithmic equation, and each equation's correlation coefficient was calculated. Additionally, the concentration error was calculated by fitting the area value of eight standards to each equation.

\subsubsection{LOD and LOQ}

The LOD and quantification (LOQ) were estimated in accordance with ICH guidelines [? ]. LOD and LOQ are defined as a signal-to-noise ratio of 3:1 and 10:1, respectively.

\subsubsection{Precision}

The repeatability of the analytical method was calculated to assess its precision. The precision was measured in terms of the relative standard deviation (RSD, \%). Equation (1) was used to calculate the RSD of the area value obtained from each standard of $50 \mu \mathrm{g} / \mathrm{mL}$. 
Furthermore, intra-day and inter-day precision were obtained by consecutively injecting nine working standards on the same day and three working standards on different days.

$$
\operatorname{RSD}(\%)=\left(\frac{\text { Standard Deviation }}{\text { Mean }}\right) \times 100
$$

\subsubsection{Accuracy}

To investigate the recovery and validity of the analytical method, the recovery was calculated using Equation (2). FOSs, monosaccharides, di-saccharides standards $(50 \mu \mathrm{g} / \mathrm{mL})$ were added $10 \mathrm{mg}, 1 \mathrm{mg}$, and $100 \mu \mathrm{g} / \mathrm{mL}$ very dark-grade maple syrup samples, respectively. The recovery was then calculated from the area values of the added sample, standard product, and maple syrup sample using the following equation.

$$
\text { Recovery }(\%)=\left(\frac{\text { Observed conc. }-C_{\text {maple }}}{\text { Added conc. }}\right) \times 100
$$

where $C_{\text {maple }}$ is the determined concentration of saccharides in maple syrup.

\subsection{Size Exclusion Chromatography}

The excluding of the large-molecular-weight components in the maple sap was carried out by Ultracel $10 \mathrm{kDa}$ ultrafiltration discs (Merck Millipore, Darmstadt, Germany). To separate the target oligosaccharide and other saccharides in maple sap, the filtrate was applied on an Econo-column ( $1 \mathrm{~m} \times 25 \mathrm{~mm}$ internal diameter; Bio-Rad Laboratories, Inc., Hercules, CA, USA) packed with Sephadex G-15 gel (GE Healthcare, Boston, MA, USA). A Bio-Rad fraction collector Model 2110 (Bio-Rad Laboratories, Inc.) was used to collect each fraction, which consisted of 200 drops. Water was used for elution and washing.

\subsection{Nuclear Magnetic Resonance (NMR)}

The structural analysis of the target oligosaccharide was carried out using a JNM-ECA 800 model (Jeol Resonance, Inc., Tokyo, Japan) and ${ }^{1} \mathrm{H}$ and ${ }^{13} \mathrm{C}-\mathrm{NMR}$ spectroscopic data were recorded at 800 and $200 \mathrm{MHz}$, respectively. The unidentified oligosaccharide for NMR analysis was dissolved in $\mathrm{D}_{2} \mathrm{O}$. Radiant-selected pulse sequences were used to ${ }^{1} \mathrm{H}-{ }^{1} \mathrm{H}$ correlation spectroscopy (COSY), ${ }^{1} \mathrm{H}-{ }^{13} \mathrm{C}$ heteronuclear single-quantum correlation spectroscopy (HSQC), ${ }^{1} \mathrm{H}-{ }^{13} \mathrm{C}$ heteronuclear multiple-bond correlation spectroscopy (HMBC) and ${ }^{1} \mathrm{H}-{ }^{1} \mathrm{H}$ nuclear overhauser effect spectroscopy (NOESY) spectra. Chemical shifts are given in the $\delta$-scale (ppm), and coupling constants $J_{\mathrm{H}, \mathrm{H}}$ are given in $\mathrm{Hz}$.

\subsection{Statistical Analysis}

The statistical analyses were performed using Microsoft Office Excel 365 (Redmond, Washington, WA, USA). All experiments were performed at least three times. All data are expressed as the mean \pm standard deviations (S.D.) of the mean.

\section{Results}

\subsection{Developments of the Method for the Separation of FOSs}

To analyze FOS using HPLC with CAD, the separation method was optimized using glucose, fructose, sucrose, and FOSs (1-kestose, nystose, and 1-fructofuranosylnystose) standards (Figure ??). At room temperature, isocratic runs were investigated at a flow rate of $1 \mathrm{~mL} / \mathrm{min}$ flow with acetonitrile:water ratios of 60:40, 65:35, 70:30, 75:25, and 80:20 were investigated (Figure S1). When performing the isocratic elution with acetonitrile at a concentration of $70 \%$ or higher, good resolution between each standard was obtained.

Subsequently, to compactly separate FOSs while maintaining the separation of monoand disaccharides, we decided to perform gradient elution after $10 \mathrm{~min}$. The mobile phase consisted of a 70:30 isocratic ratio for $10 \mathrm{~min}$, followed by a 70\% to 50\% acetonitrile linear gradient for $20 \mathrm{~min}$ (Figure ??A). A linear gradient elution had a slight effect on the 1-kestose and nystose peaks, but it did shorten the retention time of the 1-fructofuranosylnystose 
peak. The retention times for 1-kestose, nystose, and 1-fructofuranosylnystose were significantly reduced for a linear gradient of $75 \%$ to $50 \%$ acetonitrile (Figure ??B). In addition, the shapes of these peaks were improved. The retention times of the sucrose, 1-kestose, nystose, and 1-fructofranosylnystose peaks were significantly reduced in linear gradients of acetonitrile from $80 \%$ to $50 \%$. The peak retention times for 1-kestose, nystose, and 1-fructofuranosylnystose were $24.2 \mathrm{~min}, 26.4 \mathrm{~min}$, and $28.1 \mathrm{~min}$, respectively. Tri-, tetra-, and penta-saccharides were retained for about $4 \mathrm{~min}$, narrowing the separation window (Figure ??C). These findings indicated that the multi-gradient method using $75 \%$ acetonitrile as the starting eluent can be used to analyze mono- to penta-saccharides including FOSs uniformly with high resolution. Therefore, since it may provide sufficient resolution for the analysis of small oligosaccharides as well as fructosyl oligosaccharides in maple syrup, isocratic gradient elution with $75 \%$ acetonitrile was selected as the optimal condition. On the other hand, the polymerization degree of oligosaccharides that could be analyzed by this analytical method was investigated. This analytical method was able to analyze up to hepta-saccharides $30 \mathrm{~min}$ after analyzing inulin oligosaccharides (Figure S2).
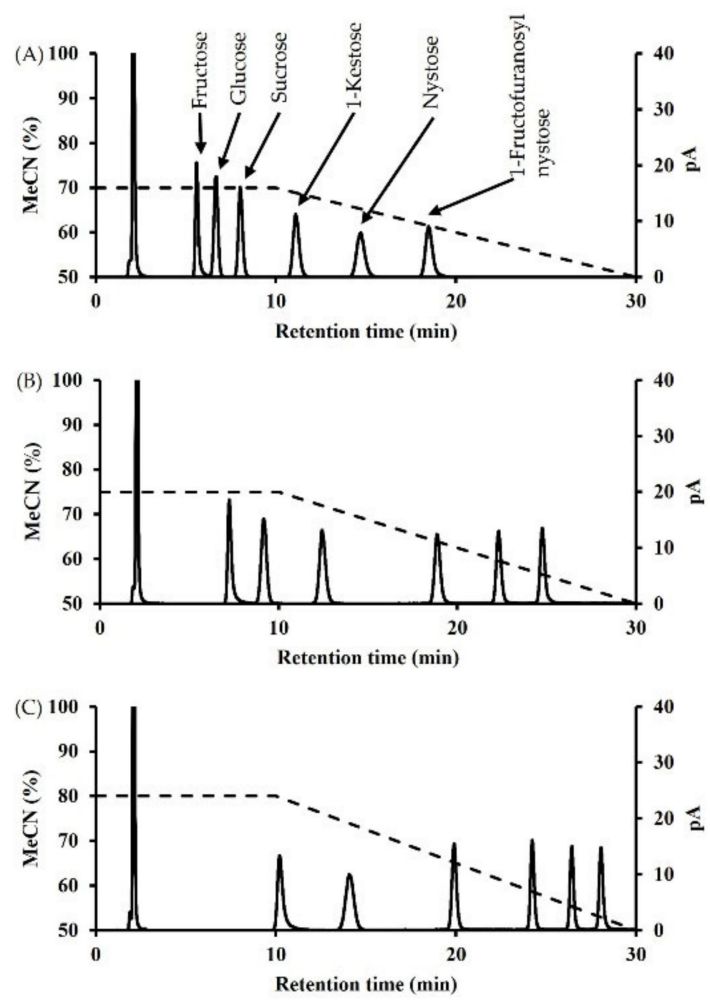

Figure 2. Chromatographic differences using saccharide standard by multi-gradient elution with (A) 70\% acetonitrile, (B) 75\% acetonitrile, and (C) $80 \%$ acetonitrile isocratic elution for 0 to $10 \mathrm{~min}$, followed by reduction to $50 \%$ acetonitrile over 10 to $30 \mathrm{~min}$.

\subsection{Validation of the Optimized Method}

The nonlinear calibration range, correlation coefficient $\left(\mathrm{R}^{2}\right), \mathrm{LOD}, \mathrm{LOQ}$, intra-day precision, inter-day precision, and recovery of this analytical method were all evaluated. Table ?? summarizes the data pertaining to method validation. Each quantification range for all standards includes $0.5-100 \mu \mathrm{g} / \mathrm{mL}$, with three digits including LOQ. It can be presented as a quadratic equation $y=a x^{2}+b x+c$ from the responses of evaluated ranges. The correlation coefficient $\left(R^{2}\right)$ expressed linearity of at least $R^{2}>0.999$ for all saccharides. The LOD and LOQ for all standards were $0.25 \mu \mathrm{g} / \mathrm{mL}$ and $0.5 \mu \mathrm{g} / \mathrm{mL}$, respectively. Precision was $0.9 \%$ or less intra-day and $1.8 \%$ or less inter-day. The recovery of all standards was calculated using the maple syrup sample described below, and good values of $91 \%$ or higher were obtained for all standards. 
Table 1. Validation data for the optimized analytical method using HILIC-CAD, including concentration range, linear equation, correlation coefficients, LOD, LOQ, intra- and inter-day precision, and accuracy.

\begin{tabular}{|c|c|c|c|c|c|c|c|}
\hline \multicolumn{2}{|c|}{ Saccharides } & Fructose & Glucose & Sucrose & 1-Kestose & Nystose & $\begin{array}{l}\text { Fructo- } \\
\text { furanosyl } \\
\text { Nystose }\end{array}$ \\
\hline \multicolumn{2}{|c|}{$\begin{array}{l}\text { Concentration range } \\
(\mu \mathrm{g} / \mathrm{mL})\end{array}$} & $0.5-100$ & $0.5-100$ & $0.5-100$ & $0.5-100$ & $0.5-100$ & $0.5-100$ \\
\hline \multicolumn{2}{|c|}{ Linear equation } & $\begin{array}{c}y=-0.0003 x^{2} \\
+0.1193 x+ \\
0.0279\end{array}$ & $\begin{array}{c}y=-0.0003 x^{2} \\
+0.1268 x+ \\
0.0577\end{array}$ & $\begin{array}{c}y=-0.0003 x^{2} \\
+0.1237 x+ \\
0.0781\end{array}$ & $\begin{array}{c}y=-0.0003 x^{2} \\
+0.1149 x+ \\
0.0539\end{array}$ & $\begin{array}{c}y=-0.0002 x^{2} \\
+0.0980 x+ \\
0.0329\end{array}$ & $\begin{array}{c}y=-0.0002 x^{2} \\
+0.0995 x+ \\
0.0241\end{array}$ \\
\hline \multicolumn{2}{|c|}{$\mathrm{R}^{2}$} & 0.9998 & 0.9998 & 0.9996 & 0.9998 & 0.9997 & 0.9999 \\
\hline \multicolumn{2}{|c|}{$\begin{array}{c}\mathrm{LOD} / \mathrm{LOQ} \\
(\mu \mathrm{g} / \mathrm{mL})\end{array}$} & $0.25 / 0.5$ & $0.25 / 0.5$ & $0.25 / 0.5$ & $0.25 / 0.5$ & $0.25 / 0.5$ & $0.25 / 0.5$ \\
\hline \multirow{2}{*}{$\begin{array}{l}\text { Precision } \\
\quad(\%)\end{array}$} & $\begin{array}{l}\text { Intra-day } \\
(n=9)\end{array}$ & 0.733 & 0.768 & 0.639 & 0.668 & 0.848 & 0.840 \\
\hline & $\begin{array}{l}\text { Inter-day } \\
\quad(n=3)\end{array}$ & 0.630 & 1.46 & 1.02 & 1.67 & 1.46 & 1.71 \\
\hline \multicolumn{2}{|c|}{$\begin{array}{c}\text { Accuracy } \\
(\%)\end{array}$} & 96.5 & 91.7 & 94.3 & 92.3 & 98.2 & 97.9 \\
\hline
\end{tabular}

\subsection{Analysis of Carbohydrates Observed in Maple Syrup}

This optimized method was compared to the RID method by analyzing maple syrup samples. Figure ?? showed the carbohydrates found in very dark-grade maple syrup using RID and CAD. The mobile phase consisted of a 75:25 isocratic ratio for $10 \mathrm{~min}$, followed by a $75 \%$ to $50 \%$ acetonitrile linear gradient for $20 \mathrm{~min}$. As a result, only major saccharides such as sucrose were observed by the RID method. However, due to the baseline drift caused by linear gradient elution, peaks could not be observed after sucrose (Figure ??A). On the other hand, in the CAD method, for monosaccharides, the peak of psicose was observed, which could not be derivatized, as well as fructose. This optimized method separated the saccharides found in maple syrup into a tetra-saccharide. The peaks of 1-kestose and nystose were observed, but 1-fructofuranosylnystose was not found in maple syrup (Figure ??B).

On the other hand, any unidentified peaks were observed at 18-21 min of this chromatogram, which was predicted to be a trisaccharide based on the retention time. These unidentified saccharides were named "mapletrioses". Mapletrioses were identified as three distinct peaks and were numbered in ascending order of retention time. Mapletriose1 was the fourth highest peak in maple syrup after sucrose, glucose, and fructose, and it slightly overlapped with the peak of 1-kestose. Mapletriose1 and 1-kestose had a resolution of 1.4. On the other hand, mapletriose 2 and 3 were present in trace amounts. Although we attempted to identify mapletrioses using standards available on the general reagent market, these saccharides were unable to be identified.

Subsequently, saccharides quantification in all grades of maple syrup was performed using standard calibration curves (Table ??). The amount of fructose and glucose in maple syrup increased as the season progressed. Though sucrose amount did not change significantly by well controlled brix, the sucrose amount decreased to approximately $55 \%$ in the very dark grade. Additionally, 1-kestose and nystose levels increased as the season progressed, as did monosaccharides. On the other hand, we also attempted to quantify mapletriose 1 from its area value using the 1-kestose calibration curve. The predictive quantity of mapletriose 1 increased with the late season, and each grade maple syrup contained 20.6, 19.6, 31.2, and $40.6 \mu \mathrm{g} / 10 \mathrm{mg}$. Since the predicted values of mapletriose 1 in the saccharides composition of maple syrup were not negligible, we decided to identify it. 
(A)

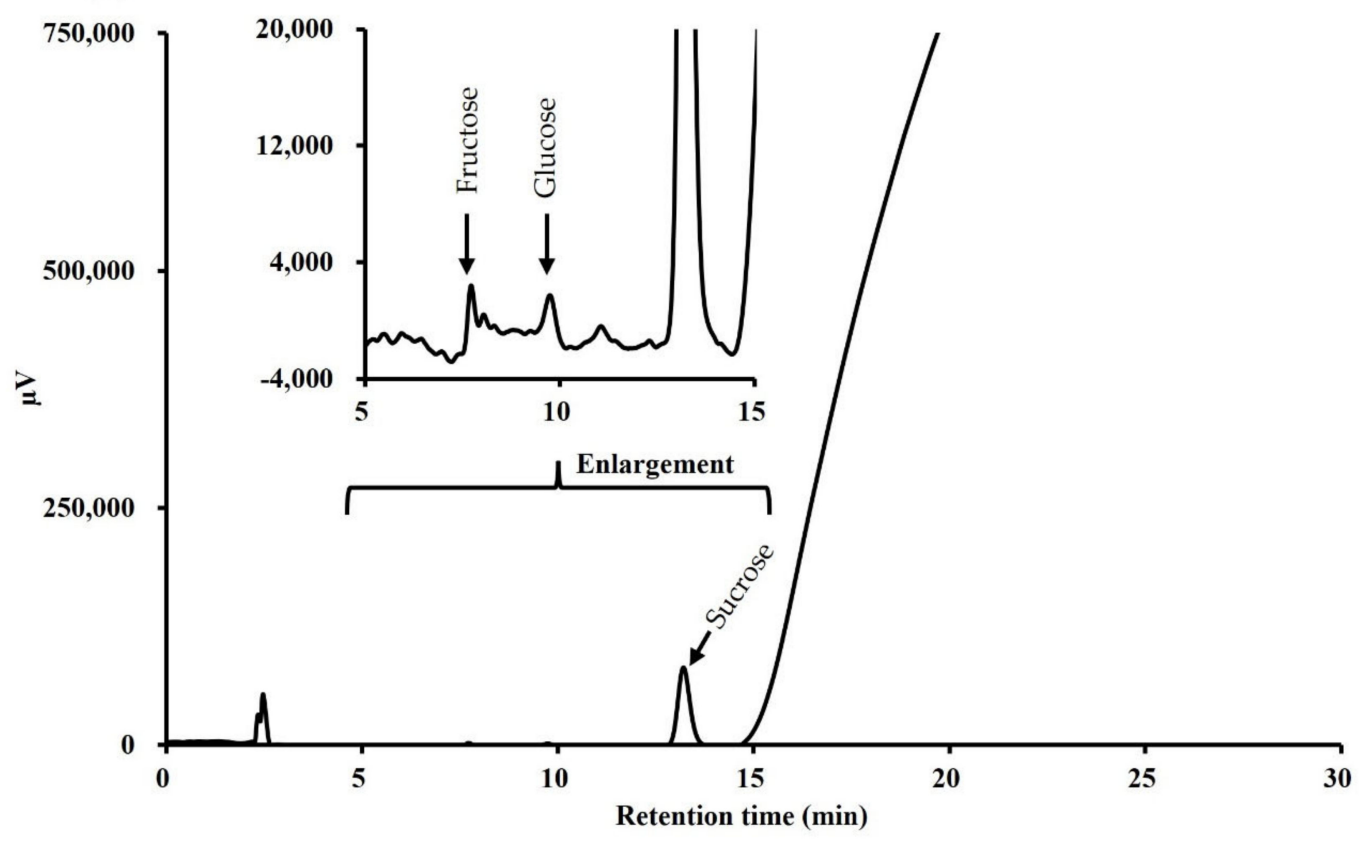

(B)
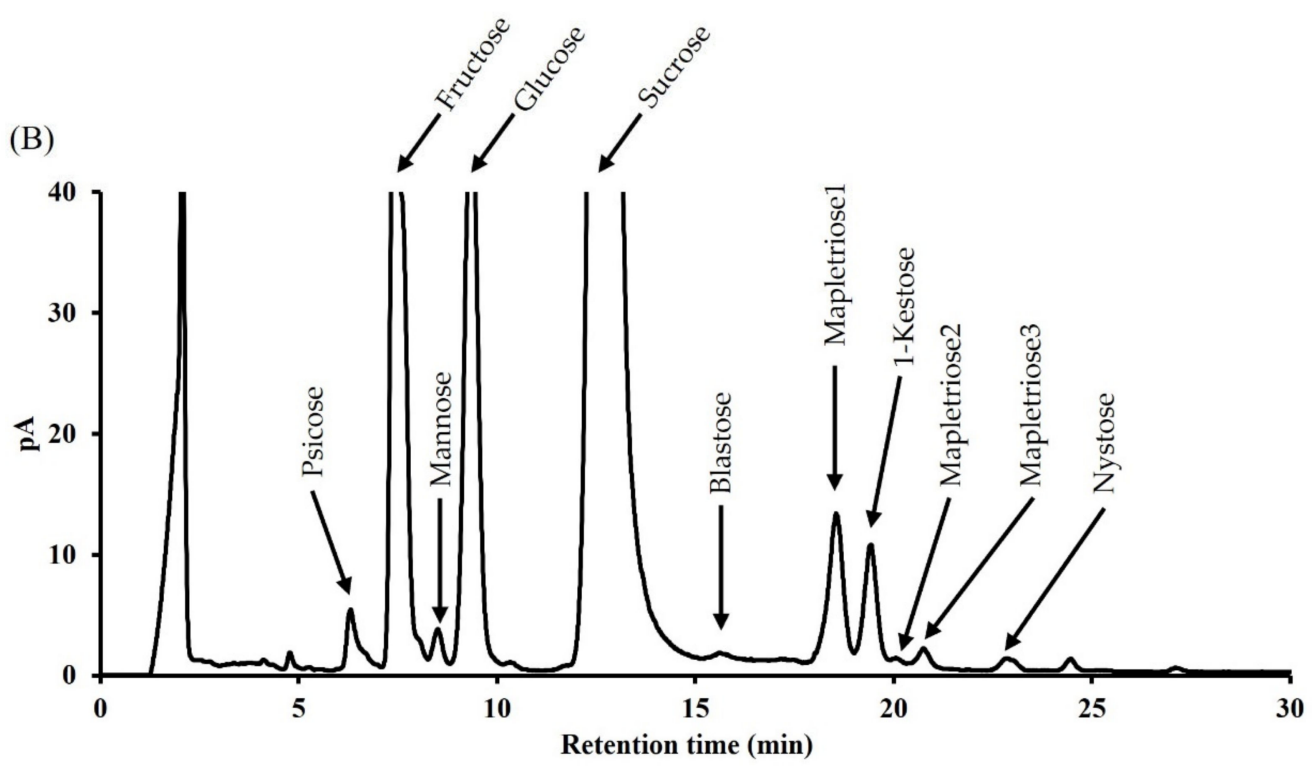

Figure 3. Comparison of the chromatograms of maple syrup at a common concentration of $10 \mathrm{mg} / \mathrm{mL}$ detected by RID (A) and $\operatorname{CAD}(\mathbf{B})$.

Table 2. The concentration of saccharides in all grades of maple syrup under investigation.

\begin{tabular}{ccccc}
\hline Variables & Golden & Amber & Dark & Very Dark \\
\hline Fructose $(\mu \mathrm{g} / 10 \mathrm{mg})$ & $21.3 \pm 0.146$ & $41.7 \pm 0.295$ & $65.6 \pm 0.442$ & $163 \pm 1.46$ \\
Glucose $(\mu \mathrm{g} / 10 \mathrm{mg})$ & $31.6 \pm 0.152$ & $55.1 \pm 0.396$ & $83.3 \pm 0.464$ & $198 \pm 2.12$ \\
Sucrose $(\mathrm{mg} / 10 \mathrm{mg})$ & $5.98 \pm 0.159$ & $5.94 \pm 0.138$ & $6.04 \pm 0.115$ & $5.49 \pm 0.0506$ \\
$\quad$ Mapletriose1 $(*)$ & $20.6 \pm 1.23$ & $19.6 \pm 0.474$ & $31.2 \pm 0.491$ & $40.6 \pm 0.573$ \\
$\quad(\mu \mathrm{g} / 10 \mathrm{mg})$ & $5.05 \pm 0.357$ & $10.1 \pm 0.383$ & $13.6 \pm 0.142$ & $25.3 \pm 0.510$ \\
1 -Kestose $(\mu \mathrm{g} / 10 \mathrm{mg})$ & $0.244 \pm 0.0155$ & $0.593 \pm 0.00395$ & $1.45 \pm 0.0191$ & $3.08 \pm 0.0483$ \\
Nystose $(\mu \mathrm{g} / 10 \mathrm{mg})$ & &
\end{tabular}

Data are presented as mean \pm S.D. $\left({ }^{*}\right)$ The concentration of mapletriose1 was predicted using the calibration curve of 1-kestose. 


\subsection{Structural Analysis of Mapletriose1 by NMR}

For structural analysis of mapletriose1, this oligosaccharide was fractionated and purified from maple sap in accordance with our previous study [? ]. Two-dimensional NMR analysis was performed to clarity the structure of mapletriose1. The C-2 and C-2" of fructose residues were observed in the one-dimensional carbon spectrum at $\delta_{C} 106.42$ ppm and $\delta_{\mathrm{C}} 106.43 \mathrm{ppm}$, respectively. In the one-dimensional proton spectrum, the $\mathrm{H}-1^{\prime}$ of glucoside residue resonated at $\delta_{\mathrm{H}} 5.39 \mathrm{ppm}$ with a $J_{\mathrm{H}, \mathrm{H}}$ value of $3.9 \mathrm{~Hz}$. In addition, the $\mathrm{H}-6^{\prime}$ of glucoside residue was identified at $\delta_{\mathrm{H}} 3.77-3.79 \mathrm{ppm}$ from the correlation spectrum COSY, HSQC, and DEPT. These proton signals ( $\mathrm{H}-1$ and $\mathrm{H}-6$ of glucose residue) correlated with fructofuranoside $C-2$ and C-2" position $\left(\delta_{C}: 106.42-106.43\right)$ in the two-dimensional HMBC spectrum. Protons corresponding to the $\mathrm{H}-4$ fructose residue showed correlations to the proton $\mathrm{H}-1^{\prime}$ of a glucose residue in the two-dimensional NOESY spectrum. All of the other signals from one-dimensional and correlation spectroscopy (i.e., COSY, HSQC, HMBC, NOESY, and DEPT) were assigned as a group (Table ??, Figure S3). Based on these findings, mapletriose 1 is predicted to be a trisaccharide called neokestose $(2,6-\mathrm{O}-$ $\beta$-d-fructofuranosyl- $\alpha$-d-glucopyranosyl-1,2-O- $\beta$-d-fructofuranoside), and its structural formula is shown in Figure ??.

Table 3. ${ }^{1} \mathrm{H}(800 \mathrm{MHz})$ and ${ }^{13} \mathrm{C}(200 \mathrm{MHz})-\mathrm{NMR}$ spectral data of neokestose in $\mathrm{D}_{2} \mathrm{O}$.

\begin{tabular}{cccccc}
\hline \multirow{5}{*}{ Residue } & Position & $\delta_{\mathbf{C}}$ & $\delta_{\mathbf{H}}$ & $J_{\mathbf{H}, \mathbf{H}}$ & Type \\
\hline \multirow{5}{*}{ Fruf $\beta$} & 1 & 64.15 & 3.64 & - & $\mathrm{s}$ \\
& 2 & $106.42-106.43$ & - & - & - \\
& 3 & 78.92 & 4.2 & 8.9 & $\mathrm{~d}$ \\
& 4 & 76.64 & 4.05 & $8.7,8.7$ & $\mathrm{dd}$ \\
& 5 & 84.07 & $3.87-3.89$ & - & $\mathrm{m}$ \\
Glcp $\alpha$ & 65.07 & 3.83 & $12.1,11.9$ & $\mathrm{dd}$ \\
\hline \multirow{5}{*}{ Fruf $\beta$} & $1^{\prime}$ & 94.72 & 5.39 & 3.9 & $\mathrm{~d}$ \\
& $2^{\prime}$ & 73.73 & 3.55 & $3.9,9.9$ & $\mathrm{dd}$ \\
& $3^{\prime}$ & 75.15 & 3.73 & $9.6,9.6$ & $\mathrm{dd}$ \\
& $4^{\prime}$ & 71.89 & 3.51 & $9.9,9.4$ & $\mathrm{dd}$ \\
& $5^{\prime}$ & 74.25 & $3.91-3.94$ & - & $\mathrm{m}$ \\
& $6^{\prime}$ & 63.02 & $3.77-3.79$ & - & $\mathrm{m}$ \\
\hline $1^{\prime \prime}$ & 62.90 & 3.65 & - & $\mathrm{s}$ \\
& $2^{\prime \prime}$ & $106.42-106.43$ & - & - & - \\
& $3^{\prime \prime}$ & 79.48 & 4.18 & 8.7 & $\mathrm{~d}$ \\
& $4^{\prime \prime}$ & 77.04 & 4.13 & $8.1,8.5$ & $\mathrm{dd}$ \\
& $5^{\prime \prime}$ & 83.86 & $3.85-3.87$ & - & $\mathrm{m}$ \\
& $6^{\prime \prime}$ & 65.15 & 3.82 & $11.9,12.1$ & $\mathrm{dd}$ \\
\hline
\end{tabular}

Chemical shifts $\left(\delta_{\mathrm{C}}\right.$ and $\left.\delta_{\mathrm{H}}\right)$ and coupling constants $\left(J_{\mathrm{H}, \mathrm{H}}\right)$ are shown in ppm and $\mathrm{Hz}$, respectively.<smiles>OC[C@H]1O[C@@](CO)(O[C@H]2O[C@H](CO[C@@]3(CO)O[C@H](CO)[C@H](O)[C@H]3O)[C@H](O)[C@@H](O)[C@@H]2O)[C@H](O)[C@@H]1O</smiles>

Figure 4. The structure of neokestose, purified and isolated from maple sap. The NMR chemical shift values for each number are shown in Table ??. 


\section{Discussion}

An HILIC column is commonly used for saccharide analysis. In this study, an aminotype HILIC column was used. Its distinguishing feature is the separation of saccharides based on the degree of polymerization. The retention time can, thus, be used to predict the degree of polymerization of unidentified saccharides. However, using only isocratic elution, it is difficult to rapidly analyze the saccharide with a degree of polymerization of three or more. As a result, multi-gradient elution was used to analyze these saccharides rapidly and with high sensitivity. If highly polymerizable saccharides or mono- and disaccharides are expected to be present in samples, it may be preferable to analyze them with acetonitrile at 70 and $80 \%$ concentrations, respectively. However, because our target in this study was fructosyl oligosaccharides in maple syrup, we used $75 \%$ acetonitrile isocratic elution for $10 \mathrm{~min}$ followed by linear gradient to $50 \%$ acetonitrile. In addition, inulin was analyzed using this optimized method, and up to hepta-saccharides could be analyzed within $30 \mathrm{~min}$, which is comparable to the analysis time of PAD-based methods specialized for saccharides analysis [? ? ? ? ]. Furthermore, we validated this optimized method and demonstrated its reliability with good results. Therefore, this optimized method is also suitable for routine analysis of fructosyl oligosaccharides such as FOS.

Subsequently, we used this optimized method to analyze saccharides in maple syrup. In the current study, we found 1-kestose, nystose, and several unidentified tri-saccharides referred to as "mapletrioses" from maple syrup based on the carefully analyzed FOSs of maple syrup. Recent studies have analyzed the saccharides in maple syrup using analytical methods using PAD, but there are no reports of these saccharides [? ]. Because 1-kestose is the smallest unit of inulin and nystose is fructosylated 1-kestose, these results support previous studies that suggested that maple syrup contained inulin [? ]. Our previous studies could suppress the rise in plasma glucose levels [? ? ]. This function became increasingly noticeable as the season progressed. Because maple syrup contains various saccharides, including fructosyl oligosaccharides, we hypothesized that this function is related to the saccharide content of maple syrup. As a result of quantifying FOSs in maple syrup in the current study, it was discovered that FOSs contents increased as the season progressed, as with maple syrup's function. These FOS have been linked to the indigestible function [? ]. Therefore, the content of these FOSs may be related to maple syrup's function in suppressing the increase in plasma glucose level.

Our previous study found blastose in maple syrup [? ]. This study also showed that blastose levels were rising due to invertase digestion of maple syrup. Invertase, also known as $\beta$-fructofuranosidase, can cleave a glycosyl bond between fructose and glucose from the fructose side. This occurrence suggested that maple syrup contained an unidentified fructosyl oligosaccharide that was considered to be fructosyl blastose. On the other hand, blastose is a disaccharide composed of fructose and glucose with a $\beta(2 \rightarrow 6)$ linkage, and its structure is not shared by 1-kestose or nystose. As a result of our prediction that a mapletriose is the fructosylated blastose, we set out to isolate and purify mapletriose 1 from maple sap to determine its structure. The purified and isolated mapletriose1 was analyzed by LC-ESI-MS/MS, and $\mathrm{m} / \mathrm{z}$ of this saccharide was 503.1 as $[\mathrm{M}-\mathrm{H}]^{-}$. This was consistent with the predicted mass of tri-saccharides. Furthermore, NMR analysis was performed to analyze the detailed structure of mapletriose1, including the linkages of its constituent saccharides. NMR spectroscopy showed that mapletriose 1 is a fructosyl blastose called neokestose composed of two fructose molecules and glucose. Neokestose is also known as neo-inulin type fructosyl oligosaccharide or neo-FOS. While it has been established that neokestose is a transfructosylation product of levansucrase [? ? ], little is known about its quantitative composition in natural foods because its standard is not available on the general reagent market.

In blastose, C-2 of fructose is linked to C-1 of glucose, a structural feature of neokestose (Figure S4). In addition, blastose has been reported to inhibit glycosidase activity. Because the structure of neokestose includes blastose, a functional oligosaccharide, we expect neokestose to have some function similar to blastose. As a result, in future research, we 
should examine the function of neokestose. Furthermore, we believe that clarifying this observation will lead to the detailed mechanism by which maple syrup suppresses the rise in plasma glucose level.

In contrast, four unidentified peaks, including mapletriose2 and 3, were confirmed in the current study. It is expected that qualitative analysis will be complicated without standards. However, further studies are needed to identify these peaks via isolation, purification, and structural analysis of these compounds to reveal the saccharide profile of maple syrup fully.

\section{Conclusions}

In this study, we used CAD to optimize the analysis methods for fructosyl oligosaccharides in order to clarify the saccharide profile in maple syrup. This method is simple and compact, and it can analyze up to hepta-saccharides within $30 \mathrm{~min}$. In addition, we used this analytical method to precisely determine the mono- and di-saccharides and fructosyl oligosaccharides, including FOS, in maple syrup of all grades. Maple syrup contained sucrose, glucose, and fructose as major saccharides; it also contained FOS such as 1-kestose and nystose. Furthermore, we discovered a fructosyl oligosaccharide called neokestose in maple syrup. This fructosyl oligosaccharide is rarely reported in natural foods. Because of their structural characteristics, these fructosyl oligosaccharides, including FOSs, may be related to the function of maple syrup.

Supplementary Materials: The following are available online at https://www.mdpi.com/article/10 .3390/foods10123160/s1, Figure S1: Chromatograms of saccharide standards in different isocratic conditions, Figure S2: Chromatograms of inulin saccharides, Figure S3: The 2D NMR spectra of neokestose, Figure S4: The structures of blastose and neokestose with the blastose part depicted in red.

Author Contributions: Conceptualization, A.T.; methodology, K.S. and K.M.; software, K.S. and K.M.; validation, K.S., K.M. and A.T.; formal analysis, K.S., K.M. and A.T.; investigation, K.S., T.Y. and A.T.; resources, A.T.; data curation, K.S. and A.T.; writing-original draft preparation, K.S. and T.Y.; writing-review and editing, T.Y. and A.T.; visualization, K.S.; supervision, A.T.; project administration, A.T.; funding acquisition, A.T. All authors have read and agreed to the published version of the manuscript.

Funding: This research received no external funding.

Data Availability Statement: The data presented in this study are available in the article and its supplementary materials.

Acknowledgments: This sample for this study was provided by Maple Farms Japan, Inc.

Conflicts of Interest: The authors declare no conflict of interest.

\section{References}

1. Skinner, C.B.; DeGaetano, A.T.; Chabot, B.F. Implications of twenty-first century climate change on Northeastern United States maple syrup production: Impacts and adaptations. Clim. Chang. 2009, 100, 685-702. [CrossRef]

2. Nagai, N.; Ito, Y.; Taga, A. Comparison of the enhancement of plasma glucose levels in type 2 diabetes Otsuka Long-Evans Tokushima fatty rats by oral administration of sucrose or maple syrup. J. Oleo Sci. 2013, 62, 737-743. [CrossRef]

3. Nagai, N.; Yamamoto, T.; Tanabe, W.; Ito, Y.; Kurabuchi, S.; Mitamura, K.; Taga, A. Changes in plasma glucose in Otsuka Long-Evans Tokushima fatty rats after oral administration of maple syrup. J. Oleo Sci. 2015, 64, 331-335. [CrossRef] [PubMed]

4. Yamamoto, T.; Nishita, T.; Taga, A. Dark-colored maple syrup treatment induces S-phase cell cycle arrest via reduced proliferating cell nuclear antigen expression in colorectal cancer cells. Oncol. Lett. 2019, 17, 2713-2720. [CrossRef]

5. Yamamoto, T.; Sato, K.; Kubota, Y.; Mitamura, K.; Taga, A. Effect of dark-colored maple syrup on cell proliferation of human gastrointestinal cancer cell. Biomed. Rep. 2017, 7, 6-10. [CrossRef] [PubMed]

6. Yamamoto, T.; Uemura, K.; Moriyama, K.; Mitamura, K.; Taga, A. Inhibitory effect of maple syrup on the cell growth and invasion of human colorectal cancer cells. Oncol. Rep. 2015, 33, 1579-1584. [CrossRef] [PubMed]

7. Ball, D.W. The chemical composition of maple syrup. J. Chem. Educ. 2007, 84, 1647-1650. [CrossRef]

8. Perkins, T.D.; van den Berg, A.K. Chapter 4 maple syrup-production, composition, chemistry, and sensory characteristics. Adv. Food Nutr. Res. 2009, 56, 101-143. 
9. Mellado-Mojica, E.; Seeram, N.P.; López, M.G. Comparative analysis of maple syrups and natural sweeteners: Carbohydrates composition and classification (differentiation) by HPAEC-PAD and FTIR spectroscopy-chemometrics. J. Food Compos. Anal. 2016, 52, 1-8. [CrossRef]

10. Taga, A.; Kodama, S. Analysis of reducing carbohydrates and fructosyl saccharides in maple syrup and maple sugar by CE. Chromatographia 2012, 75, 1009-1016. [CrossRef]

11. Sun, J.; Ma, H.; Seeram, N.P.; Rowley, D.C. Detection of inulin, a prebiotic polysaccharide, in maple syrup. J. Agric. Food Chem. 2016, 64, 7142-7147. [CrossRef]

12. Sato, K.; Nagai, N.; Yamamoto, T.; Mitamura, K.; Taga, A. Identification of a novel oligosaccharide in maple syrup as a potential alternative saccharide for diabetes mellitus patients. Int. J. Mol. Sci. 2019, 20, 5041. [CrossRef]

13. Hidaka, H.; Tashiro, Y.; Eida, T. Proliferation of bifidobacteria by oligosaccharides and their useful effect on human health. Bifid-Microflora 1991, 10, 65-79. [CrossRef]

14. Molis, C.; Flourie, B.; Ouarne, F.; Gailing, M.F.; Lartigue, S.; Guibert, A.; Bornet, F.; Galmiche, J.P. Digestion, excretion, and energy value of fructooligosaccharides in healthy humans. Am. J. Clin. Nutr. 1996, 64, 324-328. [CrossRef]

15. Li, J.; Liu, X.; Zhou, B.; Zhao, J.; Li, S. Determination of fructooligosaccharides in burdock using HPLC and microwave-assisted extraction. J. Agric. Food Chem. 2013, 61, 5888-5892. [CrossRef]

16. Der Agopian, R.G.; Soares, C.A.; Purgatto, E.; Cordenunsi, B.R.; Lajolo, F.M. Identification of fructooligosaccharides in different banana cultivars. J. Agric. Food Chem. 2008, 56, 3305-3310. [CrossRef] [PubMed]

17. Chikkerur, J.; Samanta, A.K.; Kolte, A.P.; Dhali, A.; Roy, S. Production of short chain fructo-oligosaccharides from inulin of chicory root using fungal endoinulinase. Appl. Biochem. Biotechnol. 2019, 191, 695-715. [CrossRef]

18. Zeaiter, Z.; Regonesi, M.E.; Cavini, S.; Labra, M.; Sello, G.; Di Gennaro, P. Extraction and characterization of inulin-type fructans from artichoke wastes and their effect on the growth of intestinal bacteria associated with health. BioMed. Res. Int. 2019, 2019, 1083952. [CrossRef] [PubMed]

19. Kosasih, W.; Pudjiraharti, S.; Ratnaningrum, D.; Priatni, S. Preparation of inulin from Dahlia Tubers. Procedia Chem. 2015, 16, 190-194. [CrossRef]

20. Agblevor, F.A.; Hames, B.R.; Schell, D.; Chum, H.L. Analysis of biomass sugars using a novel HPLC method. Appl. Biochem. Biotechnol. 2007, 136, 309-326. [CrossRef] [PubMed]

21. Farine, S.; Versluis, C.; Bonnici, P.; Heck, A.; Peschet, J.; Puigserver, A.; Biagini, A. Separation and identification of enzymatic sucrose hydrolysis products by high-performance anion-exchange chromatography with pulsed amperometric detection. $J$. Chromatogr. A 2001, 920, 299-308. [CrossRef]

22. Hadjikinova, R.; Petkova, N.; Hadjikinov, D.; Denev, P.; Hrusavov, D. Development and validation of HPLC-RID method for determination of sugars and polyols. J. Pharm. Sci. Res. 2017, 9, 1263-1269.

23. Pitsch, J.; Weghuber, J. Hydrophilic interaction chromatography coupled with charged aerosol detection for simultaneous quantitation of carbohydrates, polyols and ions in food and beverages. Molecules 2019, 24, 4333. [CrossRef] [PubMed]

24. Edwards, C.; Lawton, L.A. Assessment of microcystin purity using charged aerosol detection. J. Chromatogr. A 2010, 1217, 5233-5238. [CrossRef] [PubMed]

25. Moreau, R.A. The analysis of lipids via HPLC with a charged aerosol detector. Lipids 2006, 41, 727-734. [CrossRef]

26. Socia, A.; Foley, J.P. Direct determination of amino acids by hydrophilic interaction liquid chromatography with charged aerosol detection. J. Chromatogr. A 2016, 1446, 41-49. [CrossRef]

27. Fukushima, K.; Hashiguchi, K.; Suzuki, T.; Okawara, M.; Sekiguchi, Y. Recent developments in charged aerosol detection technology and applications. Chromatogr. J. Sep. Detect. Sci. 2011, 32, 161-170.

28. ICH Expert Working Group ICH Topic Q 2 (R1) Validation of Analytical Procedures: Text and Methodology Step 5 Note for Guidance on Validation of Analytical Procedures: Text and Methodology (cpmp/ich/381/95) Approval by Cpmp November 1994 Date for Coming into Operation. 1995. Available online: https://www.ema.europa.eu/en/documents/scientific-guideline/ ich-q-2-r1-validation-analytical-procedures-text-methodology-step-5_en.pdf (accessed on 7 August 2021).

29. Eggleston, G.; Wartelle, L.; Cyr, E.S. Detecting adulterated commercial sweet sorghum syrups with ion chromatography oligosaccharide fingerprint profiles. Separations 2016, 3, 20. [CrossRef]

30. Carabetta, S.; Di Sanzo, R.; Campone, L.; Fuda, S.; Rastrelli, L.; Russo, M. High-performance anion exchange chromatography with Pulsed Amperometric Detection (HPAEC-PAD) and chemometrics for geographical and floral authentication of honeys from Southern Italy (Calabria region). Foods 2020, 9, 1625. [CrossRef]

31. Corradini, C.; Cavazza, A.; Bignardi, C. High-performance anion-exchange chromatography coupled with Pulsed Electrochemical Detection as a powerful tool to evaluate carbohydrates of food interest: Principles and applications. Int. J. Carbohydr. Chem. 2012, 2012, 487564. [CrossRef]

32. Homann, A.; Biedendieck, R.; Götze, S.; Jahn, D.; Seibel, J. Insights into polymer versus oligosaccharide synthesis: Mutagenesis and mechanistic studies of a novel levansucrase from Bacillus megaterium. Biochem. J. 2007, 407, 189-198. [CrossRef] [PubMed]

33. Raga-Carbajal, E.; Munguia, A.L.; Alvarez, L.; Olvera, C. Understanding the transfer reaction network behind the non-processive synthesis of low molecular weight levan catalyzed by Bacillus subtilis levansucrase. Sci. Rep. 2018, 8, 15035. [CrossRef] [PubMed] 